\title{
CURSO AUTOINSTRUCIONAL PARA FORMAÇÃO DE MEDIADORES JUDICIAIS PARA ATUAÇÃO NA JUSTIÇA FEDERAL DA 2 ${ }^{\circ}$ EGIÃO
}

\author{
RIO DE JANEIRO/RJ MAIO/2018
}

\author{
Aline Alves de Melo Miranda Araújo - JFRJ - alinemiranda@jfrj.jus.br \\ Adriana Braulino da Silva - JFRJ - drika@jfrj.jus.br \\ Rachel Salette de Oliveira Cavalcante - JFRJ - rachel.cavalcante@jfrj.jus.br \\ Thereza Cristina Pereira Balthazar - JFRJ - thereza@jfrj.jus.br \\ Wanderley Lemgruber de Sousa - JFRJ - wlemgruber@jfrj.jus.br
}

Tipo: Relato de Experiência Inovadora (EI)

Categoria: Estratégias e Políticas

Setor Educacional: EDUCAÇÃO CORPORATIVA

\begin{abstract}
RESUMO
Os mecanismos consensuais são instrumentos efetivos de pacificação social, solução e prevenção de litígios com reduzida judicialização, quantidade de recursos e execução de sentenças. A realização de treinamentos com o objetivo de formar mediadores judiciais é uma medida de incentivo e aperfeiçoamento para adoção desses mecanismos no âmbito do Poder Judiciário. No presente estudo, é relatada e avaliada a experiência de criação do curso a distância, autoinstrucional, "Mediação Judicial" para atender necessidades de capacitação no tema dos servidores da Justiça Federal da $2^{\underline{a}}$ Região. A partir das avaliações sobre o curso feitas pelos aprendizes, constatou-se que o treinamento foi bem sucedido, tendo como pontos fortes conteúdos bem selecionados e desenvolvidos e um desenho didático que facilita a navegação e a aprendizagem. Adequar melhor os prazos e os conteúdos do curso à carga horária prevista e reavaliar estratégias didáticas que aumentem a capacidade de os aprendizes aplicarem em seu trabalho o que aprenderam são considerações surgidas das análises empreendidas e representam, na verdade, oportunidades de melhorias que precisam ser levadas em conta na busca pela excelência para o curso.
\end{abstract}

Palavras-chave: Educação a Distância, autoinstrucional, mediação judicial, mecanismos consensuais de solução de conflitos

\section{AGRADECIMENTOS}

AGRADECEMOS À JUÍZA FEDERAL DRA. FERNANDA DUARTE LOPES LUCAS DA SILVA E À DIREÇÃO DO FORO DA JUSTIÇA FEDERAL DE 1 GRAU NO RIO DE JANEIRO PELO APOIO E INCENTIVO DADOS AO PROJETO. 


\section{Introdução:}

A Constituição Federal, no art. 5, XXXV, dispõe que o direito de acesso à justiça, além de ser garantido pela vertente formal perante os órgãos judiciários, deve ser viabilizado mediante ordem jurídica justa e soluções efetivas (1988).

Alinhado com esse princípio constitucional, o Conselho Nacional de Justiça (CNJ) estabeleceu, por meio das Resoluções nำ 125/2010 e 398/2016, respectivamente, a "Política Judiciária Nacional de tratamento adequado dos conflitos de interesses no âmbito do Poder Judiciário" e a "Política Judiciária de solução consensual dos conflitos de interesses no âmbito da Justiça Federal", buscando, entre outras medidas, valorizar os mecanismos consensuais como método para resolver litígios com reduzida judicialização, quantidade de recursos e execução de sentenças.

Uma estratégia para implantação, prevista nas referidas políticas, é a organização de treinamentos para formação de mediadores judiciais. A fim de garantir uniformidade de conhecimentos, procedimentos e práticas, os diferentes órgãos judiciais podem criar seus próprios cursos, mas precisam seguir as mesmas diretrizes curriculares, estabelecidas nas Resoluções, e o mesmo material didático, desenvolvido e disponibilizado pelo CNJ. Assim, segundo as diretrizes estabelecidas, as diversas formações em mediação precisam ser realizadas em dois módulos (teórico e prático / estágio supervisionado), criados de acordo com conteúdos programáticos estabelecidos nas Resoluções e com carga horária de 40 horas, para o módulo teórico, e 60 horas, para o estágio.

A partir do momento em que foi identificada na Justiça Federal da $2^{\text {a }}$ Região a necessidade de ser organizado o curso para formação de mediadores judiciais, a Coordenadoria de Capacitação e Desenvolvimento (CCDE), da Justiça Federal de $1^{\circ}$ Grau no Rio de Janeiro (JFRJ), em parceria com o Núcleo Permanente de Métodos Consensuais de Solução de Conflitos, do Tribunal Regional Federal da 2 a Região, empreenderam os estudos necessários para planejar a melhor solução educacional diante das peculiaridades do contexto institucional e do público alvo, analisadas em conjunto com as diretrizes curriculares obrigatórias e o material didático disponibilizado pelo CNJ.

A necessidade de capacitar um grande número de pessoas em um curto prazo, o público alvo ter afinidade por tecnologia e educação a distância (EAD), os aprendizes encontrarem-se dispersos geograficamente pelos estados do Rio de Janeiro e Espírito Santo e o CNJ disponibilizar um material didático para auxiliar na produção do curso, 
material caracterizado por conteúdos que favorecem o estudo autônomo e independente, foram os principais aspectos que influenciaram na concepção da alternativa educacional apresentada neste relato, ou seja, o curso teórico, na modalidade EAD autoinstrucional, de "Mediação Judicial", com carga horária de 40 horas.

\section{Objetivo:}

Relatar e avaliar a experiência de criação e realização do curso teórico "Mediação Judicial", modalidade EAD autoinstrucional, como estratégia para formação de mediadores judiciais para atuação no âmbito da Justiça Federal da $2^{\underline{a}}$ Região.

\section{Referencial Teórico}

As mudanças na vida atual repercutem em perspectivas inéditas para a educação, impactando o mundo do trabalho e as formas como os trabalhadores são treinados e desenvolvidos. Martins (2009), ao analisar dados de pesquisa coordenada pela Abed, constatou que, cada vez mais, a EAD torna-se uma importante aliada da educação corporativa, observando que, até aquele momento, tinha sido registrado um aumento de $77 \%$ no investimento das organizações em tecnologias educacionais.

$\mathrm{Na}$ educação a distância, a mediação educacional viabilizada pelas novas tecnologias de informação e comunicação (NTICs), surgidas com a Internet, elevou o processo de ensino-aprendizagem a um patamar tecnológico nunca antes concebido. Ao mudar, significativamente, a maneira com que as pessoas se socializam, se comunicam, aprendem e ensinam, a Internet cria novas possibilidades para a educação a distância (CORCINI, 2017).

No contexto atual, o planejamento de qualquer solução educacional deverá considerar que os aprendizes estarão sempre conectados à Web e atraídos por tudo que se relaciona à tecnologia, não aceitando a antiga postura passiva de aprendizagem e nem os tradicionais métodos de ensino centrados no professor como única fonte de conhecimento (CORCINI, 2017).

Adultos que já estão no mundo corporativo e não dispõem de tempo suficiente para participarem de ações educacionais tradicionais constituem o principal público da educação a distância. A EAD garante a flexibilidade e a autonomia necessárias para viabilizar ações educacionais a quem enfrenta restrições de tempo e de espaço (NUNES, 2009). 
A autonomia e independência observadas nos aprendizes atuais favorecem não só a promoção da EAD, mas também da autoinstrução. A aprendizagem autoinstrucional acontece de forma individualizada e autodirigida, sem espaço para socializar dúvidas e receber orientações (CONSTANCIAO, 2016). Cursos EAD autoinstrucionais são desenhados didaticamente para não contarem com interferência de professor, serem autoexplicativos e abordarem de maneira objetiva e simples as temáticas, não explorando atividades e desafios complexos que possam demandar o atendimento de eventuais dúvidas (RAMOS, 2005).

Como qualquer organização contemporânea que se encontra diante do desafio de manter seus colaboradores permanentemente capacitados em um cenário institucional de constante mudança e de escassez de recursos e contando com aprendizes que apresentam restrições de tempo e de espaço, a Justiça Federal de 1ำ Grau no Rio de Janeiro (JFRJ) tem adotado a EAD autoinstrucional como uma alternativa eficaz para manter a oferta de oportunidades de treinamentos e garantir que seus servidores permaneçam atualizados.

\section{Procedimentos Metodológicos:}

Trata-se de um relato de experiência que buscou avaliar a eficácia do treinamento a distância, autoinstrucional, desenvolvido para o módulo teórico do curso de formação de mediadores judiciais, tendo sido realizadas análises quantitativas e qualitativas dos dados e das percepções dos participantes manifestas na avaliação de reação ao curso, realizada no momento de finalização da ação.

O curso EAD autoinstrucional "Mediação Judicial", com 40 horas, foi adaptado a partir de material didático disponibilizado pelo Conselho Nacional de Justiça e criado seguindo as diretrizes curriculares estabelecidas, mas sem perder o foco de atender a realidade e as necessidades de treinamento da Justiça Federal da $2^{\text {a }}$ Região. O curso foi estruturado em cinco unidades de aprendizagem: Noções Preliminares (Fundamentos da Justiça Conciliativa), Políticas Públicas em Resolução Alternativa de Disputa (RAD), Teoria dos Jogos, Teoria do Conflito e Fundamentos da Negociação, A Sessão de Mediação e Atuação do Mediador.

Cada unidade do curso foi desenhada didaticamente para acontecer de forma autoinstrucional e a distância, pelo ambiente virtual de aprendizagem Moodle. O material didático originalmente disponibilizado pelo CNJ foi adequado a recursos do Moodle que possibilitaram a apresentação dos conteúdos em formatos de áudio, livro, história em quadrinho, imagem, foto, apresentação powerpoint, vídeo e link, garantindo uma 
abordagem educacional multimídia, interativa e hipertextual para o curso. Atividades de aprendizagem, como exercícios de fixação e avaliação, foram criados utilizando a atividade "questionário" do Moodle. Os exercícios foram disponibilizados ao final de cada unidade. A avaliação de aprendizagem foi configurada para ser exibida somente após o aluno ter feito todo o curso e para aprovar apenas aqueles que obtivessem nota igual ou superior a 7,0 .

Ao final do treinamento, após a avaliação de aprendizagem, como última tarefa do curso, os participantes tiveram que fazer a avaliação de reação ao curso, respondendo um formulário online criado a partir da atividade "pesquisa", disponível no Moodle, com o objetivo reunir dados que permitissem aos gestores analisarem o curso e identificarem oportunidades de melhorias.

O instrumento da avaliação de reação foi constituído por doze assertivas, onde o aluno deveria indicar seu grau de concordância com cada uma delas: atribuir 1 significaria "não concordo" com a afirmativa e assinalar 5 representaria "concordo plenamente". Análises quantitativas foram feitas a partir dos valores médios atribuídos para cada variável e, também, para os indicadores, constituídos pelo agrupamento de variáveis afins: "Conteúdo Programático", reunindo três variáveis, e "Condições de Aprendizagem", agrupando as demais. 
Tabela 1 - Yariáxes e indicadores que integram a avaliação de reação

\begin{tabular}{|c|c|}
\hline Indicadores & Variáveis \\
\hline Conteúdo programático & $\begin{array}{l}\text { 1. O conteúdo do curso atendeu às minhas } \\
\text { necessidades de aprendizagem sobre o tema. } \\
\text { 2. O conteúdo do curso estava bem montado e de } \\
\text { aspecto agradável nas páginas e arquivos } \\
\text { utilizados, facilitando minha aprendizagem. } \\
\text { 3. Tenho condições de aplicar em meu local de } \\
\text { trabalho o que aprendi neste curso. }\end{array}$ \\
\hline $\begin{array}{l}\text { Condições de } \\
\text { aprendizagem }\end{array}$ & $\begin{array}{l}\text { 1. Foi fácil entender como entrar pela primeira vez } \\
\text { no ambiente virtual de aprendizagem. } \\
\text { 2. Foi fácil navegar no curso (telas, botões etc.) } \\
\text { e/ou utilizar os recursos necessários (fóruns, } \\
\text { chat, exercícios etc.). } \\
\text { 3. A época de realização do curso foi adequada. } \\
\text { 4. O período do curso e os prazos foram } \\
\text { adequados às atividades previstas no programa. } \\
\text { 5. Gostei de participar do curso e sei que aprendi o } \\
\text { conteúdo abordado. } \\
\text { 6. Consegui me organizar durante o curso e } \\
\text { realizei as atividades nos prazos estabelecidos. } \\
\text { 7. A equipe de Ensino a Distância esteve } \\
\text { disponível para esclarecer dúvidas sobre o uso } \\
\text { do ambiente virtual de aprendizagem e foi rápida } \\
\text { e eficaz na resolução de problemas. } \\
\text { 8. Sempre que necessitei fui bem atendido pelos } \\
\text { organizadores do curso. } \\
\text { 9. A divulgação do curso foi realizada com a } \\
\text { antecedência necessária. }\end{array}$ \\
\hline
\end{tabular}

O formulário da avaliação de reação contou, ainda, com um espaço para texto livre, onde os alunos foram orientados a registrar qualquer observação sobre o curso que julgassem necessária. A partir das respostas apuradas nesse item, foram conduzidas as análises qualitativas expostas no presente estudo de caso.

Os resultados, quantitativos e qualitativos, analisados neste estudo referem-se aos obtidos na avaliação de reação feita por 160 participantes de duas turmas do curso EAD autoinstrucional "Mediação Judicial".

\section{Apresentação e Discussão dos Resultados:}

O aproveitamento das vagas, ou seja, o percentual de servidores aprovados manteve-se o mesmo nas duas turmas analisadas, aproximadamente $70 \%$ dos cursistas obtiveram certificação no treinamento. É importante ressaltar que este é o mesmo percentual de aproveitamento observado para as demais ações EAD promovidas pela CCDE, indicando que as turmas analisadas mantiveram-se dentro do índice de aprovação esperado.

A análise dos dados quantitativos revela que, para o indicador "Conteúdo 
Programático", a variável que obteve maior avaliação foi "O conteúdo do curso atendeu às minhas necessidades de aprendizagem sobre o tema" e a que teve menor desempenho foi "Tenho condições de aplicar em meu local de trabalho o que aprendi neste curso". Embora o conteúdo do curso esteja adequado para eliminar as necessidades de capacitação no tema, parece que os alunos encontraram dificuldades para aplicar em seu trabalho aquilo que aprenderam.

Para o indicador "Condições de Aprendizagem", a variável "Foi fácil navegar no curso e utilizar os recursos necessários" foi a mais bem sucedida na avaliação dos participantes, enquanto "Consegui me organizar e realizei as atividades nos prazos estabelecidos" foi a que obteve pior desempenho para o indicador. O curso, embora bem desenhado e de fácil navegação, talvez não esteja adequadamente dimensionado à carga horária planejada.

A fim de aprofundar as considerações sobre a avaliação de reação ao curso, deve-se proceder uma análise qualitativa envolvendo os comentários feitos pelos participantes. Ao analisarmos as opiniões expressas pelos cursistas, podemos agrupar os comentários em duas grandes categorias: comentários sobre a relevância e adequação do curso oferecido e comentários sobre o curso não estar bem dimensionado quanto ao tempo previsto para o treinamento.

\section{- Transcrição literal de comentários sobre a relevância e adequação do curso oferecido:}

"Acredito que a conciliação seja o caminho para solução rápida dos conflitos que são trazidos à Justiça. $O$ curso foi bem montado e o material esteve de acordo com as expectativas. Estão de parabéns!"

“(...)Todo o conteúdo abordado foi de valor inestimável, incluindo as excelentes revisões dos exercícios (com um conteúdo extra de conhecimento), provocando em mim a enorme vontade de continuar estudando o assunto (...)."

"(...) Este curso veio a esclarecer muitas das minhas dúvidas e me deu ferramentas para que eu possa iniciar a prática da conciliação. $O$ fato do curso ter sido virtual também me possibilitou o estudo fora do horário de trabalho Agradeço a toda a equipe!"

"Achei que vídeos foram bem elucidativos e que facilitaram a aprendizagem do curso, bem como a didática utilizada em todas unidades. Por outro lado para ser um mediador eficiente requer dedicação, conhecimento e prática, vez que o mediador tem de estar em 
processo constante de especialização, leitura e empenho."

"Achei muito interessante a utilização de vídeos. Sugiro dar um enfoque maior se possível com vídeoaulas previamente gravadas. No mais achei tudo muito interessante sabendo, por obvio, que a pratica é que realmente vai me levar ao aprendizado."

"Achei o curso bem completo e dinâmico, pois além de apresentar conteúdo para ser lido, havia vídeos com explicações das técnicas e simulações de sessões de mediação, o que facilita o aprendizado e demonstra a aplicação prática do conteúdo ensinado."

\section{- Transcrição literal de comentários sobre o curso não estar bem dimensionado quanto ao tempo previsto para o treinamento.}

"Considero que deveria ser ampliado o tempo para conclusão do curso; até mesmo para uma melhor leitura e abordagem da bibliografia complementar. Considerei imprescindíveis os textos obrigatórios; os vídeos obrigatórios; muito interessantes os textos facultativo e os recomendados, dentre os demais que foram disponibilizados. Gostaria de ter tido muito mais tempo para ler com mais calma. Grata. Entretanto, considerei o curso muito amplo e eficiente."

"Poderia haver um prazo maior para encerramento do curso, por se tratar de EAD, considerando elevada carga de trabalho e pouca disponibilidade de tempo livre dos servidores lotados em Varas."

"O curso poderia ter tido um prazo maior para realização em virtude da carga horária extensa, e tendo em vista ainda que muitos precisam conciliar o horário de trabalho com o curso."

"Muitos textos para serem lidos em pouco tempo para uma boa aprendizagem."

\section{Considerações Finais:}

As análises quantitativas e qualitativas permitem concluir que o curso foi eficaz para eliminar as deficiências de treinamento do público alvo, podendo ser considerada uma estratégia educacional bem sucedida para a formação teórica de mediadores judiciais. Seus principais pontos fortes são: possuir conteúdos bem selecionados e desenvolvidos e ter um desenho didático que facilita a navegação e a aprendizagem. Os comentários feitos pelos avaliadores reforçam essas considerações. 
Adequar melhor os prazos e os conteúdos do curso à carga horária prevista e reavaliar estratégias didáticas que aumentem a capacidade de os aprendizes aplicarem em seu trabalho o que aprenderam são considerações surgidas das análises empreendidas e devem ser encaradas, na verdade, como oportunidades de melhorias que, na busca pela excelência para o curso, não podem ser ignoradas.

A formação do mediador judicial requer a participação em dois módulos, teórico e estágio, e o curso EAD autoinstrucional "Mediação Judicial" corresponde apenas ao treinamento teórico. Após a participação no módulo prático (estágio supervisionado), prevê-se que serão eliminadas muitas das dificuldades enfrentadas pelos alunos para aplicação dos conhecimentos.

\section{Bibliografia:}

BRASIL. Conselho Nacional de Justiça. Resolução no 125 de 29 de novembro de 2010. Dispõe sobre a Política Judiciária Nacional de tratamento adequado dos conflitos de interesses no âmbito do Poder Judiciário e dá outras providências. Disponível em $<$ http://www.cnj.jus.br/busca-atos-adm?documento=2579>. Acesso em 24 de abr 2018

BRASIL. Conselho Nacional de Justiça. Resolução no 398 de 4 de maio de 2016. Dispõe sobre a Política Judiciária de solução consensual dos conflitos de interesses no âmbito da Justiça Federal e dá outras providências. Disponível em <file:///C:/Users/wls/Downloads/Resolu\%C3\%A7\%C3\%A30\%20CJF\%20398.pdf>.

Acesso em 24 de abr de 2018

BRASIL. Constituição (1988). Constituição da República Federativa do Brasil. Disponível em < http://www.planalto.gov.br/ccivil_03/constituicao/constituicao.htm>. Acesso em 24 de abr de 2018

CORCINI, Luiz Fernando; MOSER, Alvino; MEDEIROS, Luciano Frontini de. Mudando maneiras para uma educação melhor: um ambiente virtual de aprendizagem 3D gamificado. In: ALMEIDA, siderly do Carmo Dahle de; MEDEIROS, Luciano Frontini de; MATTAR, João (Orgs.). Educação e tecnologias: refletindo e transformando o cotidiano. 1. ed. São Paulo: Artesanato Educacional, 2017, p. 259-284.

NUNES, Ivônio Barros. A história da EAD no mundo. In: LITTO, Fredric Michel; FORMIGA, Marcos (Orgs.). Educação a distância: o estado da arte. São Paulo: Pearson Prentice Hall, 2009, p. 2-8. 
MARTINS, Herbert Gomes. Educação corporativa: educação e treinamento nas empresas. In: LITTO, Fredric Michel; FORMIGA, Marcos (Orgs.). Educação a distância: o estado da arte. São Paulo: Pearson Prentice Hall, 2009, p. 224-229.

CONSTANCIO, F. G.; NOGUEIRA, D. X. P.; COSTA, J. P. C. L. da. Proposta de Modelo Addie Estendido com Aplicação nos Cursos Autoinstrucionais Mediados por Tecnologias na Escola Nacional de Administração Pública - XIII Encontro Virtual de Documentação em Software Livre e X Congresso Internacional de Linguagem e Tecnologia Online. 2016. Disponível em

<http://evidosol.textolivre.org/papers/2016/upload/105.pdf> Acesso em 05 abr 2018

RAMOS, D. K. Aspectos pedagógicos e tecnológicos da concepção e desenvolvimento de propostas de E-learning.Colabor@-A Revista Digital da CVA-RICESU, 2005, v. 3, n. 9 .

<http://pead.ucpel.tche.br/revistas/index.php/colabora/article/viewFile/116/99> Acesso em 05 abril 2018. 